Subscriber access provided by Caltech Library

\title{
Article
}

\section{Total Synthesis of the Norhasubanan Alkaloid Stephadiamine}

\author{
Nina Hartrampf, Nils Winter, Gabriele Pupo, Brian M. Stoltz, and Dirk Trauner
}

J. Am. Chem. Soc., Just Accepted Manuscript • Publication Date (Web): 11 Jun 2018

Downloaded from http://pubs.acs.org on June 11, 2018

\section{Just Accepted}

"Just Accepted" manuscripts have been peer-reviewed and accepted for publication. They are posted online prior to technical editing, formatting for publication and author proofing. The American Chemical Society provides "Just Accepted" as a service to the research community to expedite the dissemination of scientific material as soon as possible after acceptance. "Just Accepted" manuscripts appear in full in PDF format accompanied by an HTML abstract. "Just Accepted" manuscripts have been fully peer reviewed, but should not be considered the official version of record. They are citable by the Digital Object Identifier (DOI®). "Just Accepted" is an optional service offered to authors. Therefore, the "Just Accepted" Web site may not include all articles that will be published in the journal. After a manuscript is technically edited and formatted, it will be removed from the "Just Accepted" Web site and published as an ASAP article. Note that technical editing may introduce minor changes to the manuscript text and/or graphics which could affect content, and all legal disclaimers and ethical guidelines that apply to the journal pertain. ACS cannot be held responsible for errors or consequences arising from the use of information contained in these "Just Accepted" manuscripts. 
INTRODUCTION. Morphine and hasubanan alkaloids have inspired synthetic chemists for decades. Following the pioneering work of Gates in $1952,{ }^{[1]}$ more than 30 total and formal syntheses of morphine (1) have been published, ${ }^{[2]}$ some of them very recently. ${ }^{[3]}$ Many syntheses of hasubanonine (2) and its congeners have appeared in the literature since the isolation of the first hasubanan alkaloid was reported by Konto et al. in 1951. ${ }^{[4]}$ Therefore, it is surprising that one of the most beautiful and challenging molecules in the series, viz. stephadiamine (3), has been virtually ignored by the synthetic community.

(+)-Stephadiamine (3) was isolated from the snake vine Stephania japonica in 1984 by Taga et al. and is the only example of a norhasubanan alkaloid, which features a contracted C-ring. ${ }^{[5]}$ The absolute configuration of the natural product was elucidated by single crystal X-ray analysis of a benzoylated derivative of $\mathbf{3}$. Although $S$. japonica is used in traditional Chinese medicine to treat asthma, fever and digestive disorders, ${ }^{[6]}$ the biological activity of stephadiamine (3) has yet to be established due to a paucity of material. Structurally, 3 features a unique pentacyclic skeleton arranged around an aza[4.3.3]propellane core. It bears a total of four stereocenters, including a benzylic quaternary carbon and two adjacent $\alpha$-tertiary amines in a cis-1,2 relationship. ${ }^{[7]}$ One of these is part of an $\alpha$-amino $\delta$-lactone

which contains the benzylic oxygen often found in hasubanan alkaloids.

Scheme 1. Natural products related to stephadiamine and retrosynthesis.

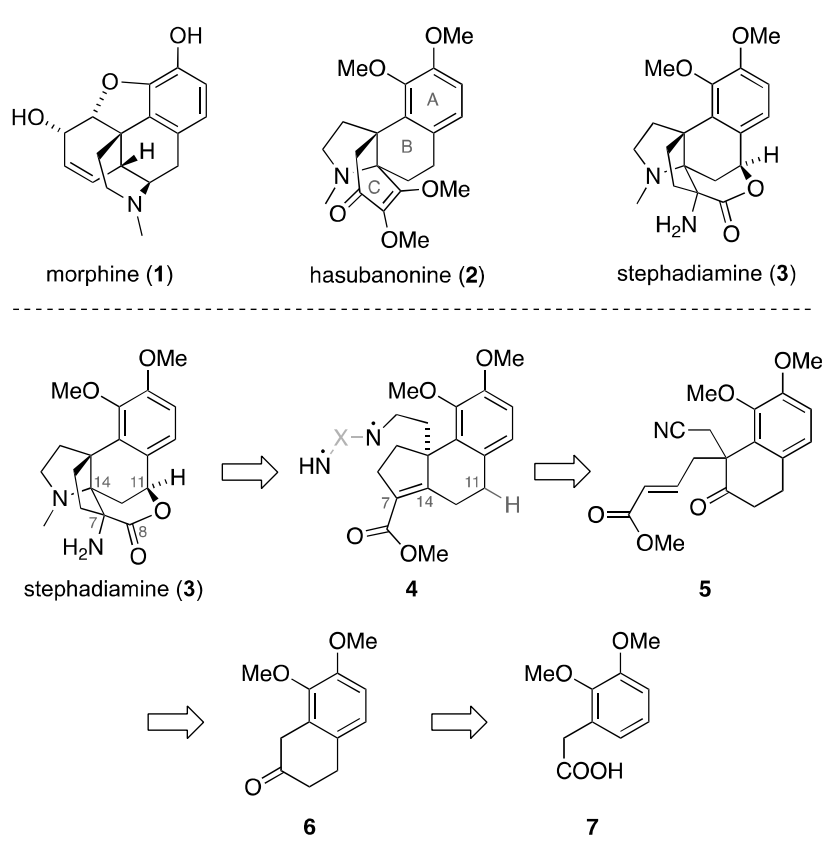

INITIAL SYNTHETIC PLAN. Motivated by these unusual structural features and our general interest in hasubanan alkaloids, ${ }^{[8]}$ we set out to explore the synthesis of stephadiamine (3). Our initial strategy called for the installation of both $\alpha$-tertiary amines and the [4.3.3]azapropellane core through a late-stage and intramolecular cis-1,2-diamination (Scheme 1). The requisite diamination substrate 4, a cyclopentene carboxylate, could be traced back to conjugated ester $\mathbf{5}$ via reductive aldol condensation. Ketone $\mathbf{5}$, in turn, could be accessed from the known $\beta$ tetralone 6. ${ }^{[9]}$ Tetralones with this substitution pattern are popular intermediates in the synthesis of hasubanan and morphinan alkaloids, ${ }^{[10]}$ but most reported preparations are lengthy, require expensive catalysts and starting materials, or are difficult to scale up. ${ }^{[9]}$ We therefore first set out to 
develop a one-pot procedure starting from the commercially available carboxylic acid 7 .

\section{Scheme 2. Synthesis of tetralone 8 and attempted aldol condensation.}
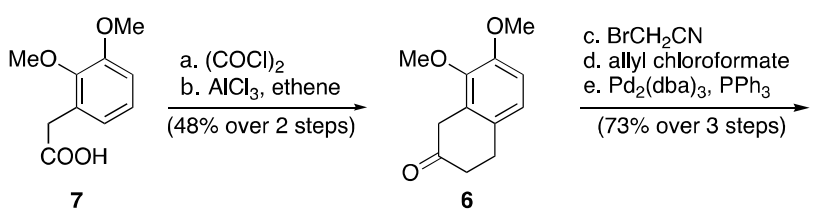

Conversion of 7 to the corresponding acyl chloride, followed by treatment with $\mathrm{AlCl}_{3}$ under an ethene atmosphere provided tetralone $\mathbf{6}$ in good overall yield and on a multigram scale (Scheme 2) ${ }^{[9]}$ Low temperatures were neces-
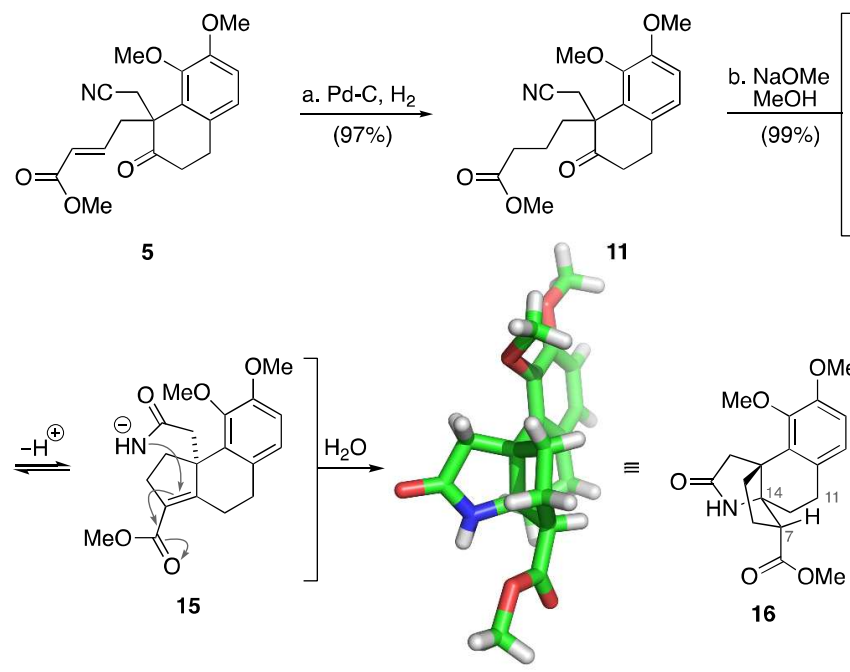

sary in this reaction to prevent competing cyclization to the corresponding benzofuranone by participation of the adjacent methoxy group. ${ }^{[11]}$ Alkylation of $\mathbf{6}$ with bromoacetonitrile under Stork conditions, ${ }^{[12]}$ followed by conversion to the enol carbonate and decarboxylative Tsuji allylation yielded tetralone $\mathbf{8}$ as a racemate with the benzylic quaternary stereocenter in place. ${ }^{[13]} \mathrm{A}$ subsequent cross metathesis with methyl acrylate then provided the conjugated ester $\mathbf{5}$ in excellent yield. ${ }^{[14]}$

DISCOVERY OF A CASCADE REACTION. With ester 5 in hand, we investigated a reductive aldol reaction to form the five-membered ring. ${ }^{[15]}$ Using Stryker's reagent, we only isolated the 1,4-reduction product (11) accompanied by lactone 9 , which is presumably formed by attack of a tertiary alkoxide onto the nitrile followed by hydrolysis, and trace amounts of the anticipated aldol product $\mathbf{1 0}$. Alternative hydride sources such as L-Selectride, $\mathrm{Rh}(\mathrm{cod})_{2} \mathrm{OTf} / \mathrm{PPh}_{3} / \mathrm{H}_{2}$, and a copper hydride formed in situ from $\mathrm{Cu}(\mathrm{OAc})_{2}$, TMDS, and $\mathrm{rac}$-BINAP only increased the yield of 9 (Scheme 2 and SI). The single crystal X-ray structure of 9 revealed a perfect anti-periplanar arrangement of the $\mathrm{C}-\mathrm{H}$-bond next to the methyl ester and the lactone $\mathrm{C}-\mathrm{O}$ bond. Despite this, we were unable to promote an elimination to the corresponding cyclopentene carboxylate.

Next, we attempted the aldol addition under conditions, which could enable the clean isolation of $\beta$-hydroxy ketone 10 with the nitrile intact (Scheme 2). In preparation for this, we hydrogenated 5 to obtain the saturated ester 11. Upon exposure of $\mathbf{1 1}$ to in situ generated sodium methoxide in methanol at $75^{\circ} \mathrm{C}$, we isolated two new products in excellent combined yield. To our pleasant surprise, these were identified as the pyrrolidinone $\mathbf{1 6}$ and its $\mathrm{C} 7$-epimer $\mathbf{1 7}$, both of which contain the aza[4.3.3]propellane core of stephadiamine (3) (Scheme 3). They are formed in a reaction cascade that presumably involves a transiently formed ester enolate

12.

\section{Scheme 3. Cascade reaction for the construction of the aza[4.3.3]propellane core.}
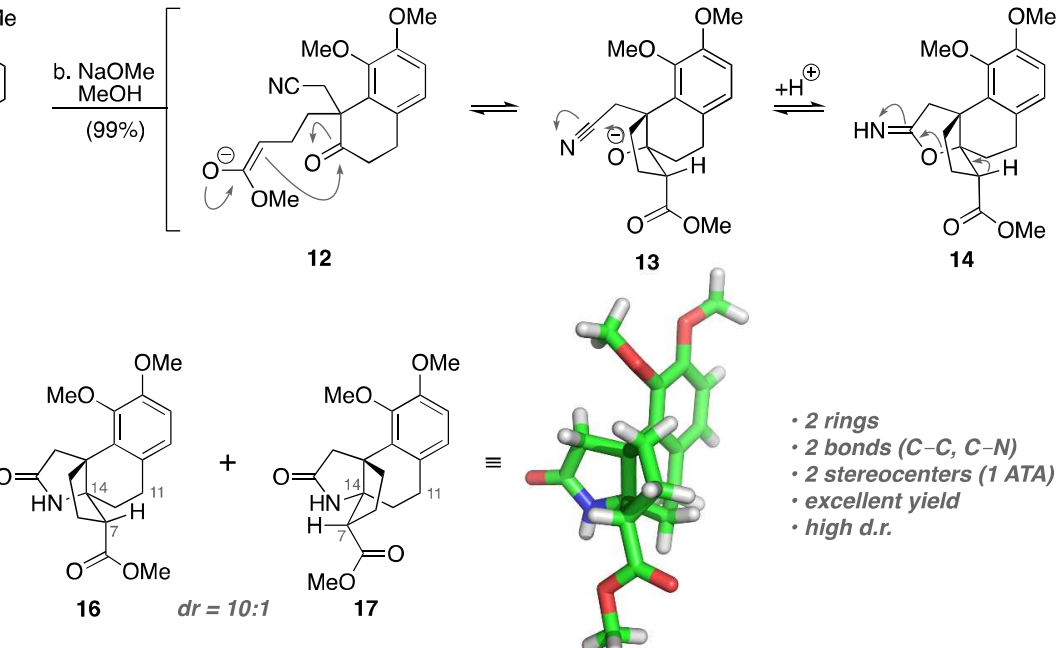

12

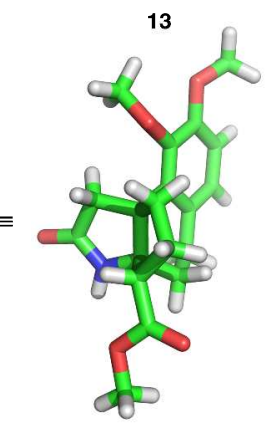

$\cdot 2$ rings

- 2 bonds (C-C, C-N)

- 2 stereocenters (1 ATA)

- excellent yield

- high d.r. 
${ }^{a}$ Reagents and conditions: (a) Pd-C (10wt\%), $\mathrm{H}_{2}$ (1 atm), EtOAc, r.t., 12 h, 97\%; (b) $\mathrm{Na}\left(1.2\right.$ eq.), $\mathrm{MeOH}, 75^{\circ} \mathrm{C}, 24$ h, $91 \%$ on 24 mmol scale, $99 \%$ on 3 mmol scale.

Intramolecular aldol addition then affords alkoxide 13, which undergoes addition to the nitrile, elimination of the intermediary imidate $(\mathbf{1 4} \rightarrow \mathbf{1 5})$, and conjugate re-addition in an aza-Michael reaction to yield the diastereomeric pyrrolidinones. This sequence of events resembles a cascade that was used in Inubushi's synthesis of cepharamine,$^{[16]}$ although in our case we construct a different heterotricyclic system with an additional stereocenter in a remarkably efficient overall reaction.

INSTALLATION OF THE DIAMINE. At this point, completion of stephadiamine (3) formally required $\mathrm{N}$ methylation, $\alpha$-amination and closure of the lactone via benzylic functionalization. While the first task could be achieved by treating the diastereomeric mixture of lactams 16 and 17 with $\mathrm{NaH}$ and MeI, the second turned out to be exceedingly difficult due to the steric hindrance of the azapropellane system.

Attempted deprotonation of $\mathbf{1 6 / 1 7}$ and exposure to a variety of electrophilic amination reagents failed to give any identifiable products and mostly resulted in the recovery of starting materials. Similarly, carboxylation under a variety of conditions, which was intended to enable a Curtius rearrangement for the installation of the second $\alpha$-tertiary amine, were unsuccessful. In addition, all efforts to epimerize the ester and to form a silyl ketene acetal failed, suggesting that the deprotonation step was the source of our frustrations.

In an attempt to increase the acidity of the $\alpha$-hydrogen, we reduced the ester moiety to the corresponding aldehyde $\mathbf{1 8}$ using DIBAL-H. Again, we only observed either decomposition or no reaction when we tried $\alpha$-aminations or carboxylation reactions. We therefore decided to resort to chemistry that would employ one of the smallest base and electrophile combinations possible: the Tollens reaction (aldol reaction followed by crossed Cannizzaro reaction). ${ }^{[17]}$ Exposure of aldehyde $\mathbf{1 8}$ to an excess of $\mathrm{KOH}$ and formaldehyde at elevated temperatures over two days afforded diol 19, which features a quaternary carbon in a highly congested position.

To convert the 1,3-diol into the $\alpha$-amino lactone moiety we tried to oxidize it to the corresponding malonate or carboxy lactone. This failed, as did our efforts to selectively protect one of the two primary alcohols. Therefore, we decided to differentiate them via benzylic oxidation. After screening multiple conditions, this could be accomplished using DDQ and $\mathrm{AcOH}$ at elevated temperatures yielding pyrane 20. ${ }^{[18]}$

${ }^{[18]}$ With one hydroxymethyl group isolated, we turned to the implementation of the second $\alpha$-tertiary amine. To this end, the primary alcohol $\mathbf{2 0}$ was converted to the carboxylic acid using Ley's conditions ${ }^{[19]}$ followed by a PinnickLindgren oxidation. ${ }^{[20]}$ Formation of the acyl azide and subsequent Curtius rearrangement in the presence of benzyl alcohol smoothly gave the Cbz-protected cis-1,2-diamine 21.

\section{Scheme 4. Installation of the diamine.}
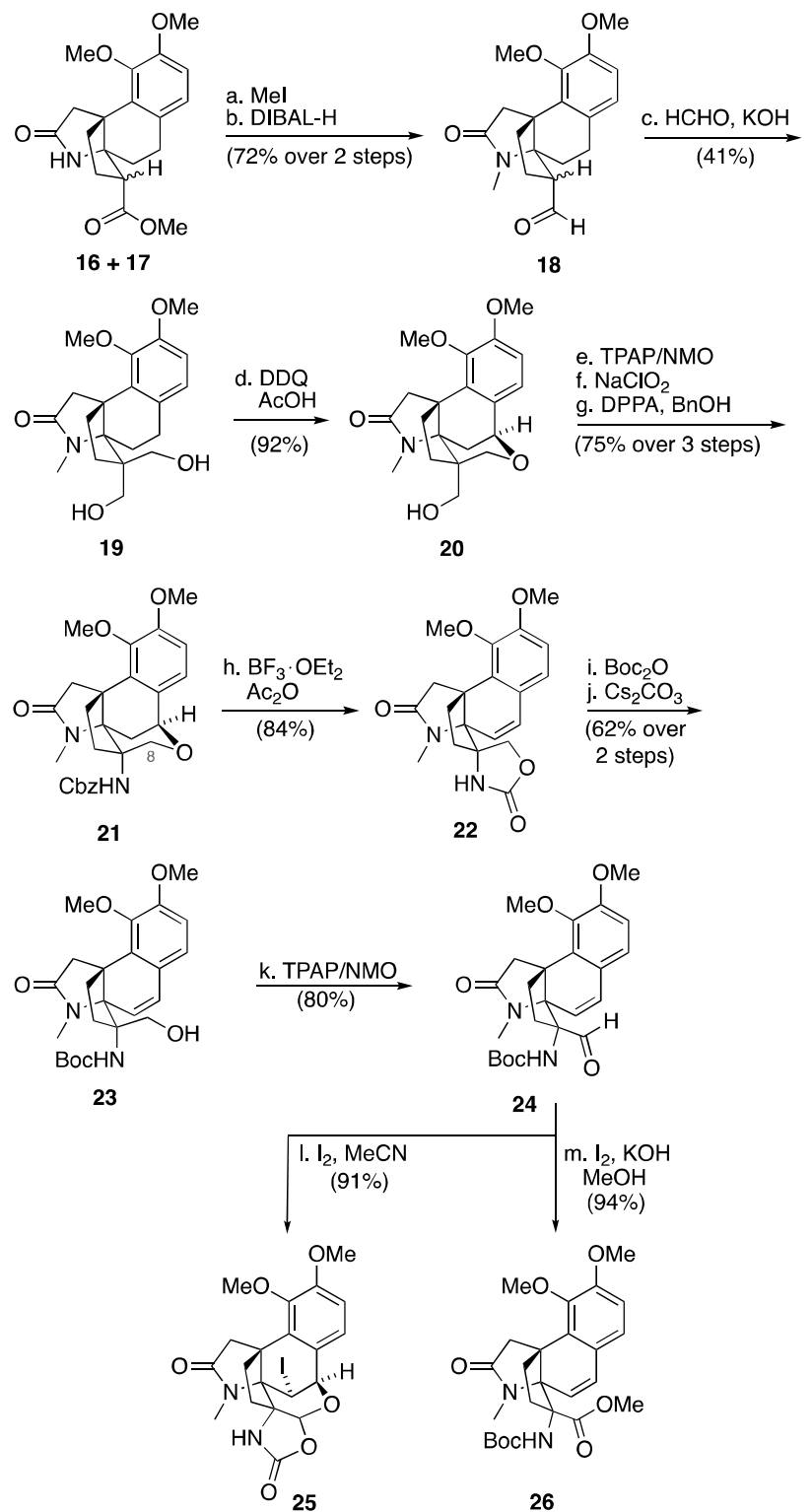

${ }^{a}$ Reagents and conditions: (a) $\mathrm{NaH}$ (1.2 eq.), MeI (1.2 eq.), DMF, $30{ }^{\circ} \mathrm{C}$, 14 h, 91\%; (b) DIBAL-H (2.5 eq.), $\mathrm{CH}_{2} \mathrm{Cl}_{2}, \square 78{ }^{\circ} \mathrm{C}, 3.5 \mathrm{~h}, 79 \%$; (c) $\mathrm{KOH}$ (10 eq.), formaldehyde (10 eq.), MeOH, $50{ }^{\circ} \mathrm{C}, 48 \mathrm{~h}, 41 \%$ (d) DDQ (10 eq.), AcOH (10 eq.), $4 \AA \mathrm{MS}, \mathrm{DCE}, 75^{\circ} \mathrm{C}, 5 \mathrm{~h}, 92 \%$; (e) TPAP (0.05 eq.), NMO (10 eq.), $4 \AA \mathrm{MS}, \mathrm{CH}_{2} \mathrm{Cl}_{2}$, r.t., $1 \mathrm{~h}, 93 \%$; (f) $\mathrm{NaClO}_{2}$ (9.2 eq.), $\mathrm{NaH}_{2} \mathrm{PO}_{4}$ (9.2 eq.), 2-methyl-2-butene, $t$-BuOH/ $\mathrm{H}_{2} \mathrm{O}$, r.t., $3 \mathrm{~h}$, 96\%; (g) DPPA (1.5 eq), NEt 3 (3 eq.), toluene, r.t., $1 \mathrm{~h}$, then $100^{\circ} \mathrm{C}, 1 \mathrm{~h}$, then $\mathrm{BnOH}$ (5 eq.), $100 \mathrm{~h}, 14 \mathrm{~h}, 84 \%$; (h) $\mathrm{BF}_{3} \square \mathrm{OEt}_{2}\left(30\right.$ eq.), $\mathrm{Ac}_{2} \mathrm{O}, 0{ }^{\circ} \mathrm{C}$ to r.t., 6.5 h, $84 \%$; (i) $\mathrm{Boc}_{2} \mathrm{O}$ (2 eq.), $\mathrm{NEt}_{3}$ (2 eq.), DMAP (0.1 eq.), THF, r.t., $17 \mathrm{~h}, 65 \%$; (j) $\mathrm{Cs}_{2} \mathrm{CO}_{3}$ (0.5 eq.), $\mathrm{MeOH}$, r.t., $12 \mathrm{~h}, 96 \%$; (k) TPAP (0.02 eq.), NMO (4.5 eq.), $4 \AA \mathrm{MS}, \mathrm{CH}_{2} \mathrm{Cl}_{2}$, r.t., $20 \mathrm{~min}, 80 \%$; (l) $\mathrm{I}_{2}$ (10 eq.), $\mathrm{MeCN}$, r.t., 24 h, $91 \%$; (m) $\mathrm{I}_{2}$ (10 eq.), $\mathrm{KOH}$ (10 eq.), $\mathrm{MeOH}$, r.t., $15 \mathrm{~min}, 94 \%$. Cbz = carboxybenzyl, DIBAL-H = diisobutylaluminum hydride, $\quad \mathrm{DDQ}=2,3$-dichloro-5,6-dicyano-1,4-benzoquinone, $\mathrm{MS}=$ molecular sieves, TPAP $=$ tetrapropyl-ammonium perruthenate, $\mathrm{NMO}=N$-Methylmorpholine $N$-oxide,$\quad$ DPPA $=$ diphenylphosphoryl .azide, $\mathrm{Boc}=$ tert-butyloxycarbonyl, DMAP $=$ 4-dimethylaminopyridine. 
Scheme 5. Completion of the synthesis.

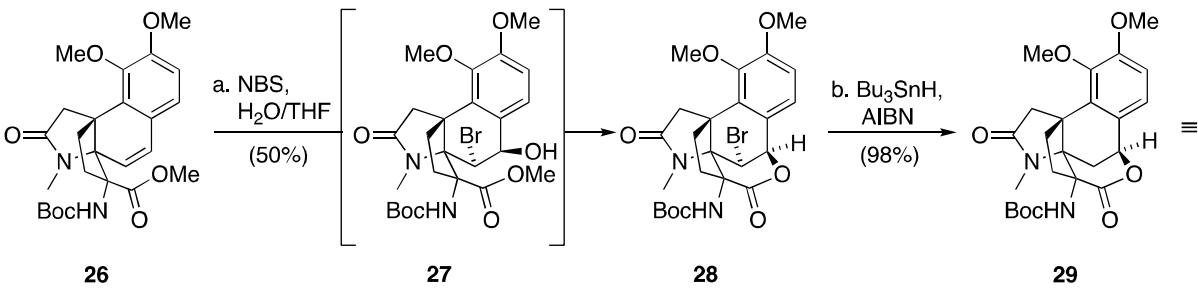

27

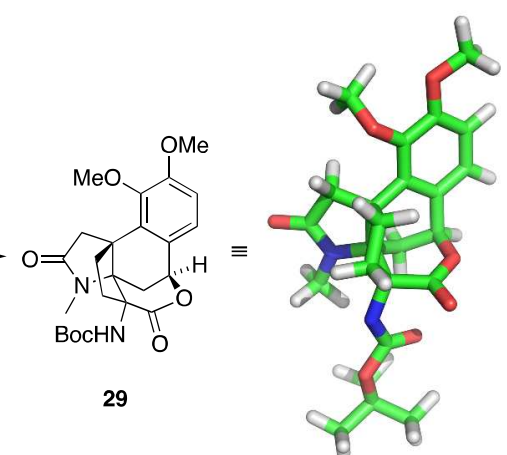

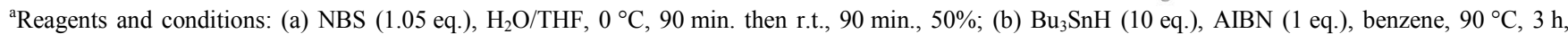
$98 \%$; (c) $\mathrm{DMS}_{\mathrm{BHH}}$ (10 eq.), THF, $0{ }^{\circ} \mathrm{C}$ to r.t., $20 \mathrm{~h}$, then $0{ }^{\circ} \mathrm{C}, \mathrm{AcOH}, 57 \%, 99 \%$ brsm; (d) TFA, DCM, $0{ }^{\circ} \mathrm{C}, 90 \mathrm{~min},<90 \%$. $\mathrm{NBS}=N-$ bromosuccinimide, $\mathrm{AIBN}=\alpha, \alpha^{\prime}$-azo-isobutyronitrile.

COMPLETION OF THE SYNTHESIS. At this stage, the completion of the synthesis would only require reduction of the lactam in $\mathbf{2 1}$, oxidation of its tetrahydropyran to a lactone and deprotection of the primary amine. Although we were aware that chances were slim due to the presence of a benzylic C,H-bond and a very electron-rich rich aromatic ring, we first explored the oxidation under a variety of conditions $\left(\mathrm{RuO}_{4}, \mathrm{KMnO}_{4}, \mathrm{CrO}_{3}, \mathrm{DMDO}\right.$, White-Chen catalyst).

Since none of the conditions led to any isolable products, we abandoned the direct oxidation of the ether $\mathbf{2 1}$ and decided to cleave the $\mathrm{C} 11-\mathrm{O}$ bond and oxidize $\mathrm{C} 8$ to the corresponding carboxylic acid followed by reclosure of the heterocycle. The reductive opening of benzylic ethers is a common transformation that can be achieved via hydrogenation or Lewis acid activation and hydride transfer. ${ }^{[21]}$ However, exposure of 21 to $\mathrm{PtO}_{2} / \mathrm{H}_{2}, \mathrm{Pd}-\mathrm{C} / \mathrm{H}_{2}$, $\mathrm{TFA} / \mathrm{Et}_{3} \mathrm{SiH}$ or $\mathrm{AcOH} / \mathrm{Et}_{3} \mathrm{SiH}$ failed to promote the reductive cleavage of the $\mathrm{C}, \mathrm{O}$ bond. We thus investigated different conditions for the conversion of the benzyl ether into the corresponding styrene via elimination. Since a variety of Lewis acids (TMSOTf, TMSCl, $\mathrm{BF}_{3} \cdot \mathrm{OEt}_{2}$ ) in different solvents did not afford the desired product, we reasoned that the elimination could be reversible and added TFAA and $\mathrm{Ac}_{2} \mathrm{O}$ to passivate the pendant alcohol. TFAA decomposed the starting material, but the use of excess $\mathrm{BF}_{3} \cdot \mathrm{OEt}_{2}$ in acetic anhydride allowed for the isolation of oxazolidinone 22. This compound was treated then with $\mathrm{Boc}_{2} \mathrm{O}$ anhydride and then hydrolyzed to yield Bocprotected amino alcohol 23. ${ }^{[22]}$

The completion the synthesis required careful orchestration of redox reactions carried out on highly hindered and sensitive substrates. Ley oxidation of primary alcohol $\mathbf{2 3}$ to the corresponding aldehyde $\mathbf{2 4}$, followed by attempted iodine mediated oxidation in acetonitrile, yielded the unusual oxazolidinone acetal 25. Multiple standard oxidation conditions, led to similar products or resulted in decomposition. However, treatment with iodine in methanol cleanly yielded methyl ester 2 26. $^{[23]}$ Since this ester could not be hydrolyzed under a variety of conditions, we attempted the direct cyclization to lactone $\mathbf{2 8}$ or $\mathbf{2 9}$. Acidcatalyzed lactonization and conventional halolactonizations were unsuccessful, presumably due to an unfavora- ble conformation of the ester. Using NBS in the presence of $\mathrm{H}_{2} \mathrm{O}$, however, we were able to regio- and stereoselectively install an intermediate bromohydrin 27, characterized by mass spectrometry, which subsequently underwent lactonization. ${ }^{[2]}$ The secondary bromide of the resultant halolactone $\mathbf{2 8}$ was removed under radical conditions to obtain the pentacyclic lactone 29, the structure of which was confirmed by single X-ray analysis. In the final steps of the synthesis, the lactam moiety in $\mathbf{2 9}$ was reduced to the corresponding pyrrolidine using borane dimethyl sulfide complex. ${ }^{[25]}$ Close monitoring of the reaction was crucial to avoid competing reduction of the strained yet sterically hindered six-membered lactone. Acidic deprotection of the primary amine finally gave racemic stephadiamine (3). The deprotection step was carried out in deuterated dichloromethane and monitored by NMR as slow cleavage of the lactone was observed upon exposure to TFA. The analytical data of synthetic 3 were in complete agreement with the limited data available from the original publication.

ASYMMETRIC APPROACH. In parallel to our racemic synthesis, we investigated an asymmetric approach to $(+)$-stephadiamine. Since the benzylic quaternary stereocenter directs the formation of all others stereocenters, we focused on the asymmetric allylation of $\mathbf{3}$. Formation of a chiral imine/enamine and reaction with a variety of electrophiles was unsuccessful. ${ }^{[2]}$ Therefore, we turned toward modern transition metal catalysis to install the benzylic quaternary stereocenter (Scheme 4). ${ }^{[27]}$ The asymmetric Tsuji allylation was investigated with a variety of chiral ligands such as $(S)-t$-Bu-PHOX (L1), $(S)-\mathrm{CF}_{3}-t-\mathrm{Bu}-$ PHOX (L2), $(S)$-QUINAP $(\mathbf{L 3}),(R, R)$ - and $(S, S)$-DACHPhenyl Trost ligand (L4), $(R, R)$-DACH-Naphthyl Trost ligand (L5) and $(R, R)$-ANDEN-Phenyl Trost ligand (L6, Table 1). These were used in different solvents and at varying concentrations and temperatures. In an initial screening, we found that a 1:2 mixture of toluene and hexane was the best solvent, providing the highest ee value across all ligand classes. The starting material was consumed in all cases and no side-products were observed.

The ligand $(S)$ - $t$-Bu-PHOX only gave $6 \% e e$, whereas the electron-deficient congener $(S)-\mathrm{CF}_{3}-t-\mathrm{Bu}-\mathrm{PHOX}$ provided $38 \%$ ee (entries 1 and 2 ). (S)-QUINAP gave a very low ee 
of $11 \%$ (entry 3 ), whereas the $C_{2}$-symmetric $(R, R)$ DACH-Phenyl Trost ligand gave the highest ee value (entry 6). Related Trost ligands resulted in a decrease of $e e$ values (entries 4 and 5). Therefore, we decided to optimize the reaction for the DACH-Phenyl Trost ligand. It was found that keeping the ligand/ $\mathrm{Pd}_{2}(\mathrm{dba})_{3}$ ratio exactly to 2.2:1 was crucial to obtain a good ee (entry 5). In additional experiments, we determined that when using this ligand, the reaction went to completion within minutes and therefore the reaction time could be shortened to 5 min (entry 6). Ultimately, treatment of the allylic carbonate 31 with $\mathrm{Pd}_{2}(\mathrm{dba})_{3}$ in the presence of chiral bisphosphine ent-L6 gave $(R)-8$ in $97 \%$ yield and $66 \%$ ee (see SI for details). ${ }^{[28]}$ After a single recrystallization we obtained an almost enantiomerically pure product, the absolute configuration of which could by established by $\mathrm{X}$-ray crystallography.

\section{Table 1 Optimization of conditions for the asym- metric decarboxylative Tsuji allylation.}
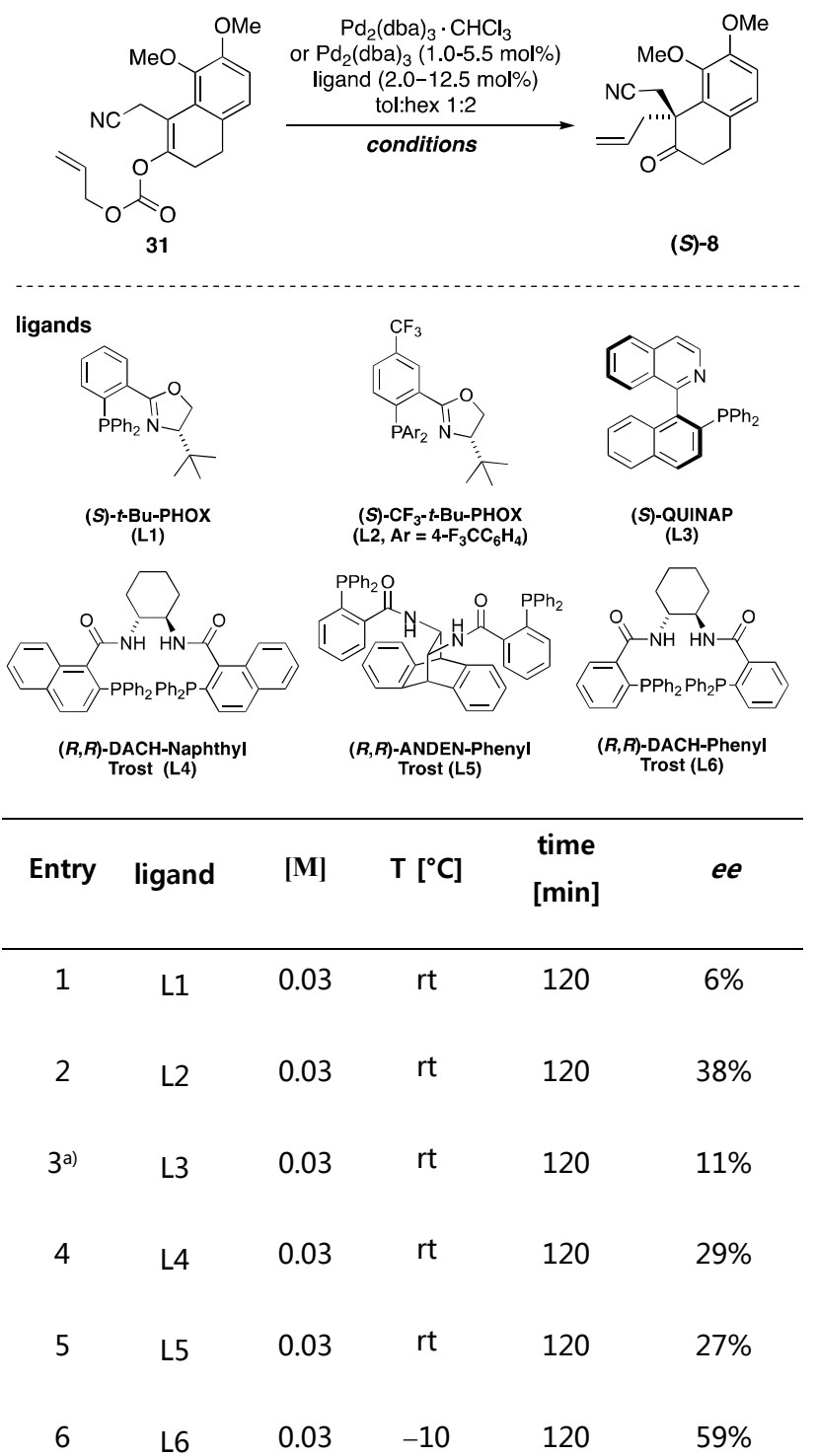

$\begin{array}{cccccc}7 & \text { L6 } & 0.03 & -10 & 120 & 66 \% \\ 8^{\mathrm{a}) \mathrm{b})} & \text { ent-L6 } & 0.003 & -10 & 5 & 66 \%\end{array}$

a $(\boldsymbol{R})-8$ was observed as the major enantiomer. ${ }^{b}$ Conditions: enol carbonate (1.0 equiv), $\mathrm{Pd}_{2}(\mathrm{dba})_{3}$ or $\mathrm{Pd}_{2}(\mathrm{dba})_{3} \cdot \mathrm{CHCl}_{3}$

$(4-10 \mathrm{~mol} \%)$, ligand $(7-12 \mathrm{~mol} \%)$ in $1: 2$ toluene:hexane, in glovebox. the reaction gave the desired $(R)$-enantiomer in $97 \%$ yield. The enantiomeric excess of this sample could be enriched to $98 \%$ ee after recrystallization

In an effort to improve the enantioselectivity of the reaction, we turned our attention towards enol catalysis, which was recently introduced by List and co-workers ${ }^{[29]}$ and allows for the direct regio- and enantioselective functionalization of unsymmetrical ketones. This is achieved by employing a chiral phosphoric acid, which selectively forms the most substituted enol, followed by asymmetric reaction with an appropriate electrophile. Under the previously reported conditions, ${ }^{[276]}$ which employ a palladium (0) source and (S)-TRIP (cat. A) as a catalyst, 32 reacted smoothly with allyl methyl carbonate $(>95 \%$ conversion, entry 1, Table 2). The desired product $(S)-\mathbf{8}$ was isolated in $84 \%$ enantiomeric excess. Upon switching to $(S)-\mathrm{H}_{8}$-TRIP (cat. B) as a catalyst, we were able to increase the enantioselectivity to $86 \%$ ee (entry 3 ).

Table 2 Optimization of conditions for the direct asymmetric $\alpha$-allylation via enol catalysis.
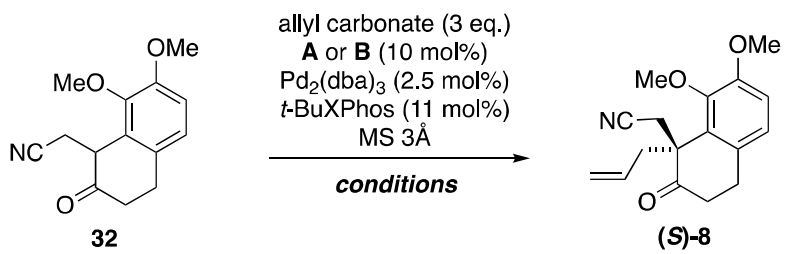

catalysts
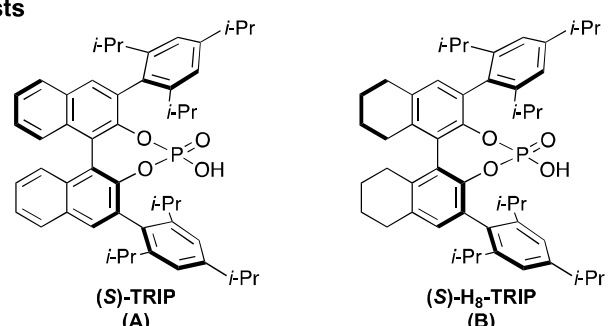

(B)

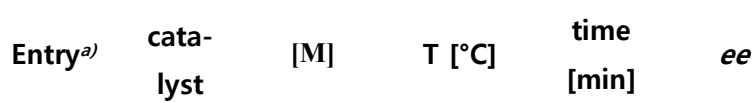

$\begin{array}{llllll}1 & \text { A } & 0.05 & \text { rt } & 18 & 84 \% \\ 2 & \text { A } & 0.025 & \text { rt } & 18 & 85 \% \\ 3 & \text { B } & 0.05 & \text { rt } & 18 & 86 \% \\ 4 & \text { B } & 0.025 & \text { rt } & 36 & 88 \%\end{array}$




\section{5}

$$
\text { B }
$$

0.01$$
6
$$$$
\text { 7b) }
$$

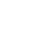$$
0.025
$$$$
\text { rt }
$$$$
8
$$$$
8
$$$$
9
$$

${ }^{\mathrm{a}}$ Conditions: allyl carbonate (1.0 equiv), $\mathrm{Pd}_{2}(\mathrm{dba})_{3}(2.5 \mathrm{~mol} \%)$, chiral acid catalyst A or B (10 mol\%), $t$-BuXPhos (11 mol\%) in cyclohexane. Full conversion by ${ }^{1} \mathrm{H}-\mathrm{NMR}$ was observed unless otherwise noted. (a) Methylcyclohexane was used as solvent; (b) $63 \%$ conversion (determined by $1 \mathrm{H} \mathrm{NMR}$ ), $63 \%$ isolated yield; (c) $85 \%$ conversion (determined by $1 \mathrm{H}$ NMR), $81 \%$ isolated yield

Upon further optimization of the reactions conditions, the desired product was isolated in $63 \%$ yield $(97 \%$ brsm) and $93 \%$ ee (entry 8 ) or in $81 \%$ yield ( $96 \%$ brsm) with $90 \%$ ee (entry 9 ).

CONCLUSIONS. In summary, we have achieved the first synthesis of the unusual alkaloid stephadiamine (3), in racemic form. Our synthesis is marked by a practical $\beta$ tetralone synthesis, the facile construction of the benzylic quaternary center through twofold alkylation, and a remarkably efficient cascade to forge the azapropellane core of 3 . The installation of the $\alpha$-amino lactone moiety proved to be difficult but could eventually be achieved using a very small base and electrophile. It also required a carefully orchestrated sequence of oxidation and reductions in a densely functionalized setting. Finally, we have elaborated a pathway for the asymmetric synthesis of stephadiamine. The building blocks developed in this context, $(\boldsymbol{R})-\mathbf{8}$ and $(\boldsymbol{S})-\mathbf{8}$, could serve as valuable intermediates in the synthesis of a variety of hasubanan and morphine alkaloids, respectively.

\section{ASSOCIATED CONTENT}

\section{Supporting Information}

The Supporting Information is available free of charge on the ACS Publications website at DOI: XXXX.

Experimental procedures, spectroscopic data and copies of NMR-spectra (PDF). CIF file for compounds 5 (CCDC 1823787), 6 (CCDC 1823794), (rac)-8 (CCDC 1823788), (R)-8 (CCDC 1823795), (S)-8 (CCDC 1823796), 9 (CCDC 1823789), 11 (CCDC 1823792), 16 (CCDC 1823793), 17 (CCDC 1823791), 20 (CCDC 1823800), $\mathbf{2 1}$ (CCDC 1823798), 22 (CCDC 1823799), 29 (CCDC 1823801), 32 (CCDC 1823786), S1 (CCDC 1823790), S2 (CCDC 1823797), (CIF files are also available free from charge on https://www.ccdc.cam.ac.uk/structures/)(CIF)

\section{AUTHOR INFORMATION}

Corresponding Author

*dirktrauner@nyu.edu

\section{ORCID}

Dirk Trauner: 0000-0002-6782-6056

Brian M. Stoltz: 0000-0001-9837-1528

Nina Hartrampf: 0000-0003-0875-6390

Gabriele Pupo: 0000-0003-3084-3888

\section{Notes}

The authors declare no competing financial interest.

\section{ACKNOWLEDGMENT}

We would like to acknowledge Dr. Anastasia Hager and Dr. Dominik Hager for their contributions in the early stages of this project. The authors thank Dr. Hong-Dong Hao and Dr. Julius R. Reyes for experimental assistance, Dr. Scott Virgil and René Rahimoff for assistance with HPLC and Dr. Peter Mayer for X-ray structure analysis. Additionally, we acknowledge the Deutsche Telekom Foundation (Ph.D. fellowship to N.H.), the LMUMentoring program (fellowship N.H.), the Otto Bayer Scholarship (fellowship to N.H.) as well as the Deutsche Forschungsgemeinschaft (SFB 749 and CIPSM) for generous funding. B.M.S. thanks the NIH-NIGMS (R01GM080269) for partial financial support of this project. Dr. Felix Hartrampf and Dr. Julius R. Reyes are acknowledged for excellent support in the course of this project and with the preparation of this manuscript.

\section{REFERENCES}

[1] M. Gates, G. Tschudi, J. Am. Chem. Soc. 1956, 78, 1380-1393.

[2] a) U. Rinner, T. Hudlicky. In Alkaloid Synthesis; H.-J. Knölker, Eds.; Springer: Berlin, Heidelberg, 2012.; b) N. Chida, in Chemistry of Opioids, Vol. 299 (Ed.: H. Nagase), Springer-Verlag Berlin, Berlin, 2011, pp. 1-28; c) U. Rinner, T. Hudlicky, Top. Curr. Chem. 2012, 309; d) J. W. Reed, T. Hudlicky, Acc. Chem. Res. 2015, 48, 674-687.

[3] a) M. Ichiki, H. Tanimoto, S. Miwa, R. Saito, T. Sato, N. Chida, Chem. Eur. J. 2013, 19, 264-269; b) J. Li, G.-L. Liu, X.-H. Zhao, J.-Y. Du, H. Qu, W.-D. Chu, M. Ding, C.-Y. Jin, M.-X. Wei, C.A. Fan, Chem. Asian J. 2013, 8, 1105-1109; c) M. Geffe, T. Opatz, Org. Lett. 2014, 16, 5282-5285; d) M. Tissot, R. J. Phipps, C. Lucas, R. M. Leon, R. D. M. Pace, T. Ngouansavanh, M. J. Gaunt, Angew. Chem. Int. Ed. 2014, 53, 13498-13501; e) S. Chu, N. Münster, T. Balan, M. D. Smith, Angew. Chem. Int. Ed. 2016, 55, 14306-14309; f) H. Umihara, S. Yokoshima, M. Inoue, T. Fukuyama, Chem. Eur. J. 2017, 23, 6993-6995; g) J. Rautschek, A. Jäger, P. Metz, Org. Lett. 2018, 20, 832-835.

[4] a) H. S. Kondo, Masakichi; Odera, Toshiko Ann. Rept. ITSUU Lab. 1951, 2, 35-43; b) M. Tomita, T. Ibuka, Y. Inubushi, Y. Watanabe, M. Matsui, Tetrahedron Lett. 1964, 5, 2937-2944; c) M. Tomita, T. Ibuka, Y. Inubushi, Y. Watanabe, M. Matsui, Chem. Pharm. Bull. 1965, 13, 538-545; d) Y. Inubushi, T. Ibuka. In The Alkaloids; R. H. F. Manske, Eds.; Academic Press: New York 1977; e) M. Matsui. In The Alkaloids; A. Brossi, Eds.; Academic Press, New York, 1988. f) S. M. King, S. B. Herzon. In The Alkaloids; H.-J. Knölker, Eds.; Academic Press, Burlington, 2014.

[5] T. Taga, N. Akimoto, T. Ibuka, Chem. Pharm. Bull. 1984, 32, 4223-4225.

[6] a) G. E. W. Tang, Chinese Drugs of Plant Origin: Chemistry, Pharmacology, and Use in Traditional and Modern Medicine 
Springer, Berlin Heidelberg, 2013; b) Y. X. F. Bingyi, C. Anmin, M. Yingfu, S. Fang, Q. Jinlin, G. Yuan, G., L. Q. Zhemin, W. Shu, Encyclopedic Reference of Traditional Chinese Medicine, Springer, Berlin Heidelberg, 2013.

[7] A. Hager, N. Vrielink, D. Hager, J. Lefranc, D. Trauner, Nat. Prod. Rep. 2016, 33, 491-522.

[8] G. Volpin, N. A. Vepřek, A. B. Bellan, D. Trauner, Angew. Chem. Int. Ed. 2017, 56, 897-901.

[9] a) M. D. Soffer, R. A. Stewart, J. C. Cavagnol, H. E. Gellerson, E. A. Bowler, J. Am. Chem. Soc. 1950, 72, 3704-3709; b) G. B. Diamond, M. D. Soffer, J. Am. Chem. Soc. 1952, 74, 4126-4127; c) M. A. McKervey, S. M. Tuladhar, M. F. Twohig, J. Chem. Soc., Chem. Commun. 1984, 129-130; d) Á. Gorka, B. Czuczai, P. Szoleczky, L. Hazai, C. Szántay, V. Háda, C. Szántay, Synth. Commun. 2005, 35, 2371-2378; e) D.-H. Wang, K. M. Engle, B.F. Shi, J.-Q. Yu, Science 2010, 327, 315-319; f) E. V. Cabrera, A. C. Gil, J. G. Ortega, L. Bedoya, J. Sánchez, A. K. Banerjee, Org. Prep. Proced. Int. 2011, 43, 364-367.

[10] a) D. A. Evans, C. A. Bryan, C. L. Sims, J. Am. Chem. Soc. 1972, 94, 2891-2892; b) J. Mulzer, G. Dürner, D. Trauner, Angew. Chem. Int. Ed. 1996, 35, 2830-2832; c) D. Trauner, Synthesis 1998, 1998, 653-664; d) J. D. White, P. Hrnciar, F. Stappenbeck, J. Org. Chem. 1999, 64, 7871-7884; e) T. X. Nguyen, Y. Kobayashi, J. Org. Chem. 2008, 73, 5536-5541.

[11] J. H. Burckhalter, J. R. Campbell, J. Org. Chem. 1961, 26, 42324235.

[12] G. Stork, A. Brizzolara, H. Landesman, J. Szmuszkovicz, R. Terrell, J. Am. Chem. Soc. 1963, 85, 207-222.

[13] a) J. Tsuji, I. Minami, I. Shimizu, Tetrahedron Lett. 1983, 24, 1793-1796; b) J. Tsuji, I. Shimizu, I. Minami, Y. Ohashi, T. Sugiura, K. Takahashi, J. Org. Chem. 1985, 50, 1523-1529; c) J. Tsuji, I. Minami, Acc. Chem. Res. 1987, 20, 140-145.

[14] a) A. K. Chatterjee, J. P. Morgan, M. Scholl, R. H. Grubbs, J. Am. Chem. Soc. 2000, 122, 3783-3784. b) J. S. Kingsbury, J. P. A. Harrity, P. J. Bonitatebus, A. H. Hoveyda, J. Am. Chem. Soc. 1999, 121, 791-799.

[15] H. Nishiyama, T. Shiomi, in Metal Catalyzed Reductive C-C Bond Formation: A Departure from Preformed Organometallic Reagents (Ed.: M. J. Krische), Springer Berlin Heidelberg, Berlin, Heidelberg, 2007, pp. 105-137.
[16] a) Y. Inubushi, T. Ibuka, M. Kitano, Tetrahedron Lett. 1969, 10, 1611-1614; b) Y. Inubushi, M. Kitano, T. Ibuka, Chem. Pharm. Bull. 1971, 19, 1820-1841.

[17] [17] a) J. Yu, X. Z. Wearing, J. M. Cook, J. Org. Chem. 2005, 70, 3963-3979; b) M. B. Smith, J. March. March's advanced organic chemistry: reactions, mechanisms, and structure; John Wiley \& Sons: Hoboken, New Jersey, 2007..

[18] H. Yi, Q. Liu, J. Liu, Z. Zeng, Y. Yang, A. Lei, ChemSusChem 2012, 5, 2143-2146.

[19] W. P. Griffith, S. V. Ley, G. P. Whitcombe, A. D. White, J. Chem. Soc., Chem. Commun. 1987, 1625-1627.

[20] a) Lindgren, B. O.; Nilsson, T., Acta Chem. Scand. 1973, 27, 888890 ; b) G. A. Kraus, M. J. Taschner, J. Org. Chem. 1980, 45, 1175-1176; c) B. S. Bal, W. E. Childers, H. W. Pinnick, Tetrahedron 1981, 37, 2091-2096.

[21] S. A. Weissman, D. Zewge, Tetrahedron 2005, 61, 7833-7863.

[22] S. J. Baker, K. J. M. Beresford, D. W. Young, Tetrahedron 2014, 70, 7221-7228.

[23] a) W. A. Ayer, W. R. Bowman, G. A. Cooke, A. C. Soper, Tetrahedron Lett. 1966, 7, 2021-2026; b) S. Yamada, D. Morizono, K. Yamamoto, Tetrahedron Lett. 1992, 33, 4329-4332.

[24] V. L. Rendina, S. A. Goetz, A. E. Neitzel, H. Z. Kaplan, J. S. Kingsbury, Tetrahedron Lett. 2012, 53, 15-18.

[25] a) M. Robba, D. Maume, Tetrahedron Lett. 1972, 13, 2333-2335; b) W.-H. Meng, T.-J. Wu, H.-K. Zhang, P.-Q. Huang, Tetrahedron: Asymmetry 2004, 15, 3899-3910; c) J.-X. Du, H.-Y. Huang, P.-Q. Huang, Tetrahedron: Asymmetry 2004, 15, 34613466.

[26] a) M. Pfau, G. Revial, A. Guingant, J. d'Angelo, J. Am. Chem. Soc. 1985, 107, 273-274; b) S. Giroux, E. J. Corey, Org. Lett. 2008, 10, 5617-5619.

[27] M. Mahlau, B. List, Angew. Chem. Int. Ed. 2013, 52, 518-533.

[28] a) J. Tsuji, I. Shimizu, I. Minami, Y. Ohashi, Tetrahedron Lett. 1982, 23, 4809-4812; b) D. C. Behenna, B. M. Stoltz, J. Am. Chem. Soc. 2004, 126, 15044-15045; c) B. M. Trost, J. Xu, J. Am Chem. Soc. 2005, 127, 2846-2847; d) J. T. Mohr, B. M. Stoltz, Chem. Asian J. 2007, 2, 1476-1491; e) B. M. Trost, J. Xu, T. Schmidt, J. Am. Chem. Soc. 2009, 131, 18343-18357.

[29] a) I. Felker, G. Pupo, P. Kraft, B. List, Angew. Chem. Int. Ed. 2015, 54, 1960-1964; b) G. Pupo, R. Properzi, B. List, Angew. Chem. Int. Ed. 2016, 55, 6099-6102; c) M. R. Monaco, G. Pupo, B. List, Synlett 2016, 27, 1027-1040.

\section{Graphic Table of Contents (TOC)}

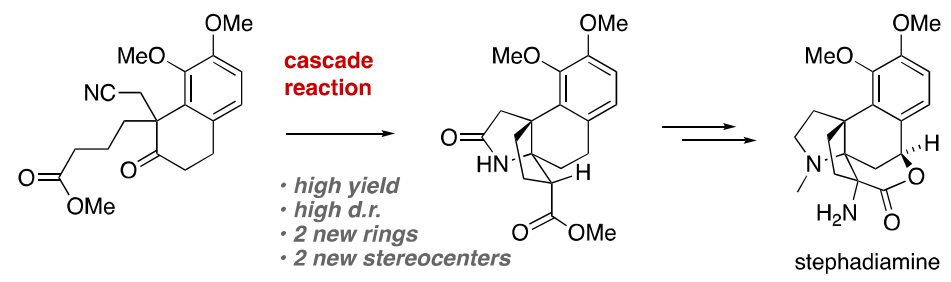

